University of South Carolina

Scholar Commons

$9-9-2013$

\title{
Short, Strong Halogen Bonding in Co-Crystals of Pyridyl Bis-Urea Macrocycles and lodoperfluorocarbons
}

\author{
Michael F. Geer \\ University of South Carolina - Columbia \\ James Mazzuca \\ University of South Carolina - Columbia, mazzuca@email.sc.edu \\ Mark D. Smith \\ University of South Carolina - Columbia, mdsmith3@mailbox.sc.edu \\ Linda S. Shimizu \\ University of South Carolina - Columbia, shimizul@mail.chem.sc.edu
}

Follow this and additional works at: https://scholarcommons.sc.edu/chem_facpub

Part of the Materials Chemistry Commons

\section{Publication Info \\ Published in CrystEngComm, Volume 15, Issue 46, 2013, pages 9923-9929. \\ (C) CrystEngComm 2013, Royal Society of Chemistry.}

This Article is brought to you by the Chemistry and Biochemistry, Department of at Scholar Commons. It has been accepted for inclusion in Faculty Publications by an authorized administrator of Scholar Commons. For more information, please contact digres@mailbox.sc.edu. 


\section{CrystEngComm}

Cite this: CrystEngComm, 2013, 15, 9923

Received 17th July 2013, Accepted 4th September 2013

DOI: $10.1039 / c 3 c e 41413 b$

www.rsc.org/crystengcomm

\section{Short, strong halogen bonding in co-crystals of pyridyl bis-urea macrocycles and iodoperfluorocarbons $\dagger$}

\author{
Michael F. Geer, James Mazzuca, Mark D. Smith and Linda S. Shimizu*
}

\section{Introduction}

Halogen bonding is an important organizing strategy for materials such as liquid crystalline materials,${ }^{1-6}$ organic semiconductors, ${ }^{2,7}$ and in the assembly of proteins and nucleic acids. ${ }^{8-12}$ This manuscript explores the propensity of the pyridyl bis-urea macrocycle to act as a Lewis base (R-B:) and form halogen bonding interactions with a series of halogen bond donors (R-X) from moderate (diiodobenzene and iodobenzene) to strong (diiodotetrafluorobenzene, diiodotetrafluoroethane, and iodopentafluorobenzene). Crystallization of the pyridyl macrocycle 1 (Fig. 1) with iodopentafluorobenzene or diiodotetrafluoroethane by slow evaporation from methylene chloride solutions affords X-ray quality crystals that show short, strong halogen bonds with these halogen bond donors. The $\mathrm{R}-\mathrm{X} \cdots \mathrm{B}$ distances range from 2.719(2) to $2.745(2) \AA$, or $78 \%$ of the sum of the van der Waals radii for O $\cdots$ I. Through systematic DFT calculations using PBE exchangecorrelation, we estimate association energies of $7.381 \mathrm{kcal} \mathrm{mol}^{-1}$ for iodopentafluorobenzene and $10.331 \mathrm{kcal} \mathrm{mol}^{-1}$ for diiodotetrafluoroethane.

In organic halides, the electron density is anisotropically distributed around the halogen resulting in a region of positive electrostatic potential along the axis of the covalent bond, termed the " $\sigma$-hole". ${ }^{13}$ This $\sigma$-hole gives the halogen a Lewis acid type nature that promotes interaction with Lewis bases, such as nitrogen and oxygen lone electron pairs, in close contact resulting in a halogen bond. The strongest examples of this are seen in the nitro-oxideiodoperfluorocarbon interactions reported by Metrangolo and Resnati. $^{14}$ Our group utilizes bis-urea macrocycles that

Department of Chemistry and Biochemistry, University of South Carolina, Columbia, SC 29208, USA. E-mail: shimizls@mailbox.sc.edu; Fax: +1 803777 9521;

Tel: +18037772066

$\dagger$ Electronic supplementary information (ESI) available: CCDC 947145-947147. For ESI and crystallographic data in CIF or other electronic format see DOI: 10.1039/c3ce41413b typically assemble through the three-centered urea hydrogen bonding motif into columnar structures and can incorporate guests within these inherently porous channels. ${ }^{15-18}$ In contrast, the pyridyl macrocycle 2 forms columnar assemblies through two separate hydrogen bonding interactions between the urea $\mathrm{N}-\mathrm{H}$ 's and two different acceptors: the urea carbonyl oxygen and the pyridine nitrogen. ${ }^{19}$ The electrostatic potential distributions of these macrocycles highlight these basic sites (shown in red) that are primarily localized on the urea oxygens and the pyridine nitrogens. We set out to examine the propensity of pyridyl bis-ureas 1 and 2 to cocrystallize with halogen bond donors. Specifically, we wanted to test the strength of the interactions that can be formed through the urea oxygen's lone pair and halogens. This manuscript reports crystal structures of halogen bond donors with pyridyl bis-urea $\mathbf{1}$, the more soluble macrocycle. We investigate the strength of these hydrogen bonding interactions through DFT calculations. The crystal structures display neutral molecules with very short and strong halogen bonds that are shorter than analogous charged species with nitro-oxide compounds.

\section{Results and discussion}

Macrocycle 1 was synthesized as reported from 2,6dibromomethylpyridine and triazinanone. ${ }^{19}$ This protected pyridyl bis-urea macrocycle lacks the urea $\mathrm{N}-\mathrm{H}$ hydrogen bond donors that drive the self-assembly in other bis-urea macrocycles to afford columnar structures. Thus, it is more soluble in typical organic solvents and provides a building block for co-crystal formation that can act only as a halogen bond or hydrogen bond acceptor. The triazinanone protecting groups can be readily deprotected to afford macrocycle 2 . Ureas have a high propensity for self-assembly and accordingly tend to have low solubility. This is true for 2 , which shows low solubility in most organic solvents. 

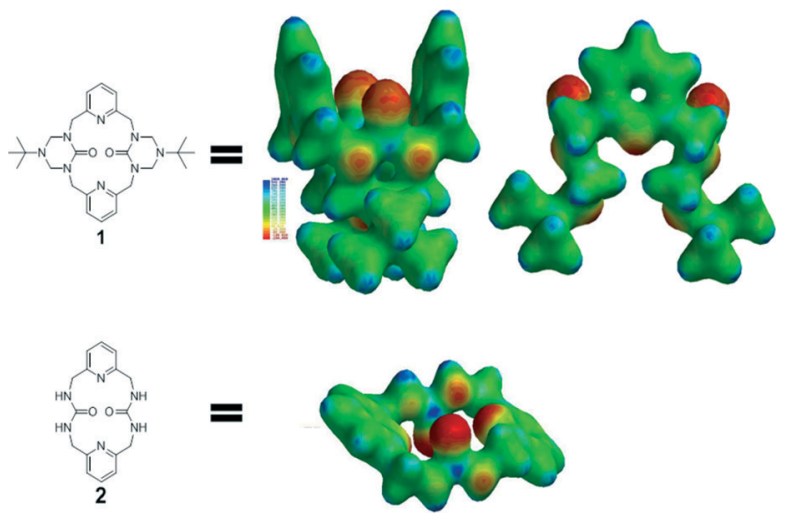

Fig. 1 Comparison of the structures and electrostatic potential distributions of the triazinanone protected pyridyl bis-urea macrocycle (1) and pyridyl bis-urea macrocycle (2) showing the more electropositive (blue), neutral (green) and electronegative (red) regions. The electrostatic potential distributions of the macrocycles are based on the DFT B3LYP calculation at the $6-31+\mathrm{G} *$ level (legend: $-200-1000 \mathrm{~kJ} \mathrm{~mol}^{-1}$ ).

We sought to compare the ability of hosts 1 and 2 to act as halogen bond acceptors. The crystal structures of these compounds have been reported. We first examined these known structures by importing their X-ray coordinates (.cif files) into Spartan' $10^{\mathrm{TM}} .{ }^{20}$ We truncated the structure to a single macrocycle and deleted the solvent molecules. The structures were then evaluated through DFT calculations at the $6-31+G^{*}$ level of theory, and the electrostatic potential was examined. Fig. 1 compares the resulting potential maps of the two structures. As expected, both show a strong electronegative potential localized at the carbonyl oxygen sites. Interestingly, the free ureas in macrocycle 2 displayed a greater electronegative potential due to the removal of the electron-withdrawing protecting group. Given the X-ray structures and electrostatic potential distributions, we conclude that 1) both macrocycles contain basic oxygen sites that could act as halogen bond acceptors, 2) the pyridine nitrogens are sterically crowded in the interior and are unlikely to interact and 3) macrocycle 2 displays a higher electronegative potential at the carbonyl oxygen versus macrocycle 1 as seen by the more intense red color. Therefore, we expect that 2 will act as a slightly stronger acceptor with its free ureas versus macrocycle 1 .

We next selected a series of five halogen bond donors to co-crystallize with macrocycles 1 and 2. Chart 1 lists the five donor compounds. Diiodotetrafluoroethane (3), diiodoperfluorobenzene (4), and perfluoroiodobenzene (5) are strong halogen bond donors. In comparison, diiodobenzene (6) and iodobenzene (7) are considered medium halogen bond donors.
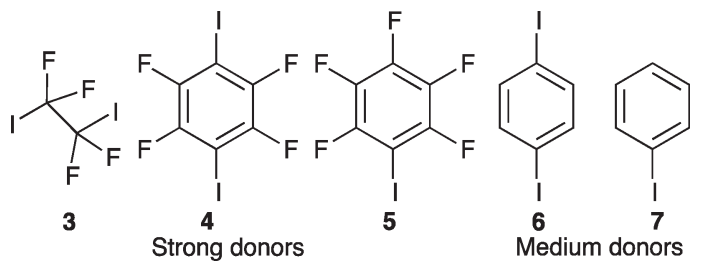

Chart 1 Halogen bond donors.
A weak halogen bond donor would include compounds such as bromo and chloro compounds.

To investigate the feasibility of forming co-crystals of macrocycles 1 and 2 and halogen bond donors, host-halide mixtures were prepared in 1:1 and 1:2 molar ratio in suitable solvents. Solutions of the more soluble macrocycle 1 were prepared in $\mathrm{CH}_{2} \mathrm{Cl}_{2}$, chloroform and THF (40 mM) in separate scintillation vials. The low solubility of 2 necessitated the use of DMSO and DMF solutions (2-5 mM). Then, to each solution, the halogenated compounds 3-7 were added, and the vials were capped loosely and allowed to slowly evaporate. For $\mathbf{1}$, crystals were obtained from $\mathrm{CH}_{2} \mathrm{Cl}_{2}$, while precipitates were observed from the other solutions. $\mathrm{X}$-ray quality crystals have not yet been obtained for 2 with these halides. The solutions of macrocycle 1 with $p$-diiodobenzene and iodobenzene gave none of the desired co-crystals and instead afforded solvates of macrocycle 1 and dichloromethane solvent. This suggests that the halogen bond donor capabilities of the iodo compounds were not sufficient to overcome the solvent interactions with the macrocycle. X-ray quality crystals were obtained from solutions of macrocycle 1 with pentafluoroiodobenzene in dichloromethane, diiodotetrafluoroethane in dichloromethane (two structures) and chloroform, and perfluorodiiodobenzene in chloroform.

\section{Macrocycle 1·pentafluoroiodobenzene $\left[\left(\mathrm{C}_{28} \mathrm{H}_{40} \mathbf{N}_{8} \mathrm{O}_{2}\right) \cdot\left(\mathrm{C}_{6} \mathrm{~F}_{5} \mathbf{I}\right)_{3}\right]$}

Slow evaporation of a 1:2 mixture of $1\left(40 \mathrm{mM}\right.$ in $\left.\mathrm{CH}_{2} \mathrm{Cl}_{2}\right)$ and pentafluoroiodobenzene afforded a colorless mass of block crystals with the formula $\left(\mathrm{C}_{28} \mathrm{H}_{40} \mathrm{~N}_{8} \mathrm{O}_{2}\right)\left(\mathrm{C}_{6} \mathrm{~F}_{5} \mathrm{I}\right)_{3}$. The compound crystallized in the space group $P \overline{1}$ of the triclinic system, consisting of one macrocycle and three independent pentafluoroiodobenzene molecules (Fig. 2). The macrocycle adopts a bowl-shaped conformation where the pyridyl nitrogens are both pointed toward the triazinanone protecting groups. The macrocycle forms three separate halogen bonds with the iodine atoms of three pentafluoroiodobenzenes. Two of these short, strong halogen bonding interactions occur between the iodo and the carbonyl oxygen. The first, to the

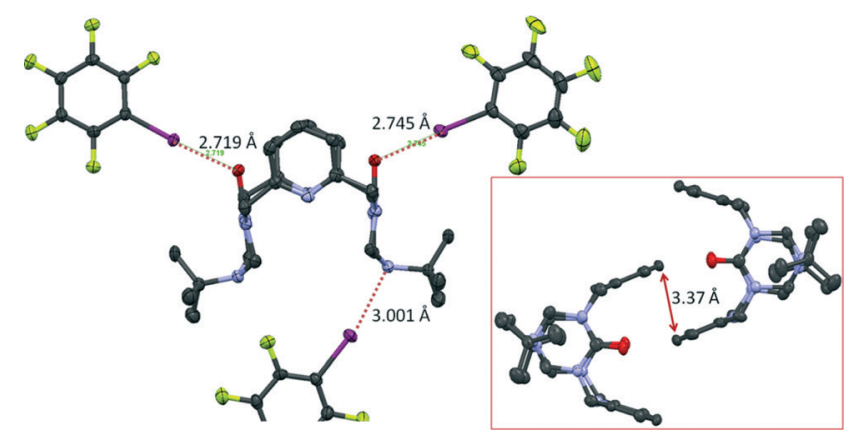

Fig. 2 Crystal structure of the protected pyridyl bis-urea macrocycle 1 with pentafluoroiodobenzene: the structure shows the extremely short $1 \cdots 0$ halogen bonds and the $1 \cdots \mathrm{N}$ halogen bond (inset) structure showing the offset aryl-aryl stacking that assists in the crystal packing. (Ellipsoids drawn at the $50 \%$ probability level, C-black, O-red, N-blue, I-purple, F-yellow; hydrogens have been removed for clarity.) 
left of the macrocycle in the figure, displays an I $\cdots \mathrm{O}$ distance of 2.719(2) $\AA$ and a C-I $\cdots \mathrm{O}$ angle of $173.71(9)^{\circ}$. The second, to the right of the macrocycle, shows an $\mathrm{I} \cdots \mathrm{O}$ distance of 2.745(2) A and a C-I $\cdots$ O angle of $177.13(9)^{\circ}$. The third halogen bond is formed with one of the triazinanone nitrogens with an $\mathrm{I} \cdots \mathrm{N}$ distance of 3.001(2) A and a C-I $\cdots \mathrm{N}$ angle of 169.32(9) ${ }^{\circ}$.

Interestingly, the two halogen bonds formed between the iodine of the pentafluoroiodobenzene and the carbonyl oxygens are only 77.7 and $78.4 \%$ of the sum of the van der Waals radii for iodine and oxygen (3.50 $\AA$ ), suggesting a very strong halogen bond. Indeed, these bonds are shorter than those reported by Resnati et al. that formed an $\mathrm{O} \cdots \mathrm{I}$ halogen bond between a nitro-oxide and iodo compound with an $\mathrm{O} \cdots \mathrm{I}$ distance of $2.745 \AA^{21}$ The third halogen bond is also a very short contact being only $85.0 \%$ of the van der Waals radii sum for nitrogen and iodine (3.53 $\AA$ ). No halogen bonds were formed with the pyridyl nitrogens as they point inwards in a conformation that is sterically disfavoured towards further interactions.

Each macrocycle further forms a "dimer" assisted by offset aryl-aryl stacking (closest $\mathrm{C}-\mathrm{C}$ distance between the parallel rings $=3.37 \AA$, Fig. 2 inset). The dimers of macrocycle 1 are separated by four "stacks" of three of the iodo compounds 5 assisted by aryl stacking with distances (center-center) of 4.01 and 3.70 $\AA$. The dimers of 1 are halogen bonded to two iodo compounds in the three stacks (down the $c$-axis) with the third halogen bonded to the nitrogen of an adjacent dimer of 1 (Fig. 3).

\section{Macrocycle 1-tetrafluorodiiodoethane $\left[\left(\mathrm{C}_{28} \mathbf{H}_{40} \mathbf{N}_{8} \mathbf{O}_{2}\right) \cdot\left(\mathrm{C}_{2} \mathbf{F}_{4} \mathbf{I}_{2}\right)\right]$}

Slow evaporation of a $1: 1$ mixture of $1\left(40 \mathrm{mM}\right.$ in $\mathrm{CH}_{2} \mathrm{Cl}_{2}$ ) and pentafluoroiodobenzene in the dark afforded colorless block crystals with the formula $\left(\mathrm{C}_{28} \mathrm{H}_{40} \mathrm{~N}_{8} \mathrm{O}_{2}\right) \cdot\left(\mathrm{C}_{2} \mathrm{~F}_{4} \mathrm{I}_{2}\right)$. The compound crystallized in the triclinic system ( $P \overline{1}$ space group) consisting of one macrocycle $\mathbf{1}$ and diiodotetrafluoroethane molecule, both located on crystallographic inversion centers. The macrocycle adopts the typical planar and anti-parallel urea orientation (Fig. 4) observed in other bis-urea macrocycles

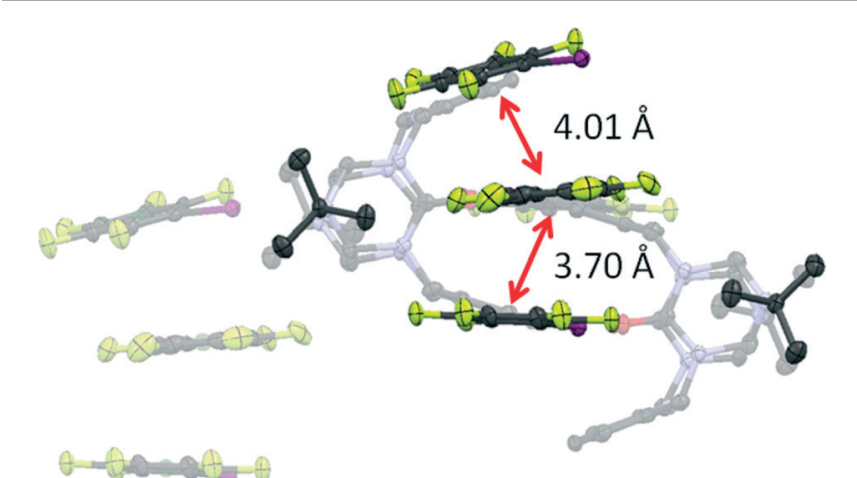

Fig. 3 The crystal packing of the halogen-bonded macrocycle 1.pentafluoroiodobenzene complex showing the offset aryl stacking of the trimers of $\mathbf{5}$ and their arrangement around the macrocycle $\mathbf{1}$ dimers. (Ellipsoids drawn at the $50 \%$ probability level, C-black, O-red, N-blue, I-purple, F-yellow; hydrogens have been removed for clarity.)

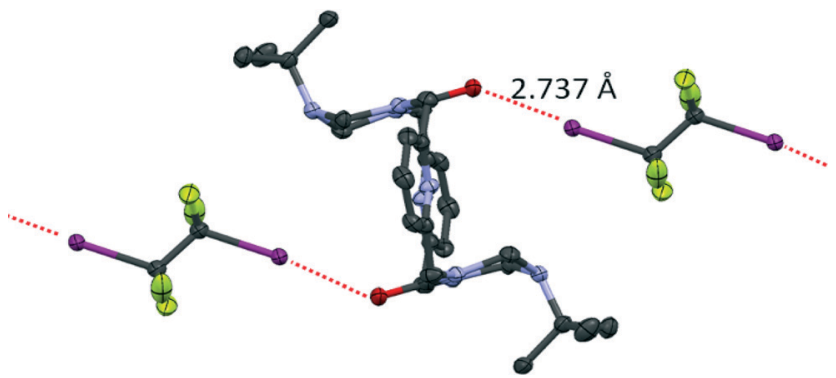

Fig. 4 The pyridyl macrocycle with halogen bonding to diiodotetrafluoroethane showing very short halogen bonding distances of $2.737 \AA(\mathrm{O} \cdots \mathrm{l})$, which is $22 \%$ shorter than the sum of the van der Waals radii $(3.50 \AA$ ). (Ellipsoids drawn at the $50 \%$ probability level, C-black, O-red, N-blue, I-purple, F-yellow; hydrogens have been removed for clarity.)

such as the $m$-xylene. ${ }^{17,22,23}$ The two carbonyl oxygens are involved in halogen bonds with separate but equivalent diiodotetrafluoroethane molecules with an $\mathrm{I} \cdots \mathrm{O}$ distance of $2.737(2)$ and a $\mathrm{C}-\mathrm{I} \cdots \mathrm{O}$ angle of $175.9(1)^{\circ}$. The $\mathrm{I} \cdots \mathrm{O}$ distance is $78.2 \%$ of the van der Waals radii sum, which suggests a very strong halogen bond. Also, the second lone pair of electrons of the carbonyl oxygen is involved in a weak $\mathrm{C}-\mathrm{H}-\mathrm{O}$ hydrogen bond with the methylene $\mathrm{C}-\mathrm{H}$ of an adjacent macrocycle (C-H $\cdots \mathrm{O}$ distance of $3.414 \AA$ and $\mathrm{C}-\mathrm{O} \cdots \mathrm{H}$ angle of $140.4^{\circ}$ ). In comparison to literature examples of co-crystals of diiodotetrafluoroethane with oxygen acceptors such as 1,4-dioxane, hexamethylphosphoramide (HMPA) or $\mathrm{N}$-methylmorpholine, this halogen bonding interaction is shorter. ${ }^{24,25}$ However, in the study of Chu et al., both lone pairs of the single oxygen HMPA acceptor in these structures are involved in the interactions with separate $\mathrm{C}_{2} \mathrm{~F}_{4} \mathrm{I}_{2}$ donors with an $\mathrm{I} \cdots \mathrm{O}$ distance of 2.864(1) and 2.835(1) $\AA$, respectively. ${ }^{25}$

Fig. 5a shows the space-filling model of the linear chain that is formed by the halogen-bonded complex $\left[\left(\mathrm{C}_{28} \mathrm{H}_{40} \mathrm{~N}_{8} \mathrm{O}_{2}\right)\left(\mathrm{C}_{2} \mathrm{~F}_{4} \mathrm{I}_{2}\right)\right]$ and the overall crystal packing of the complex (Fig. $5 \mathrm{~b}$ ) that

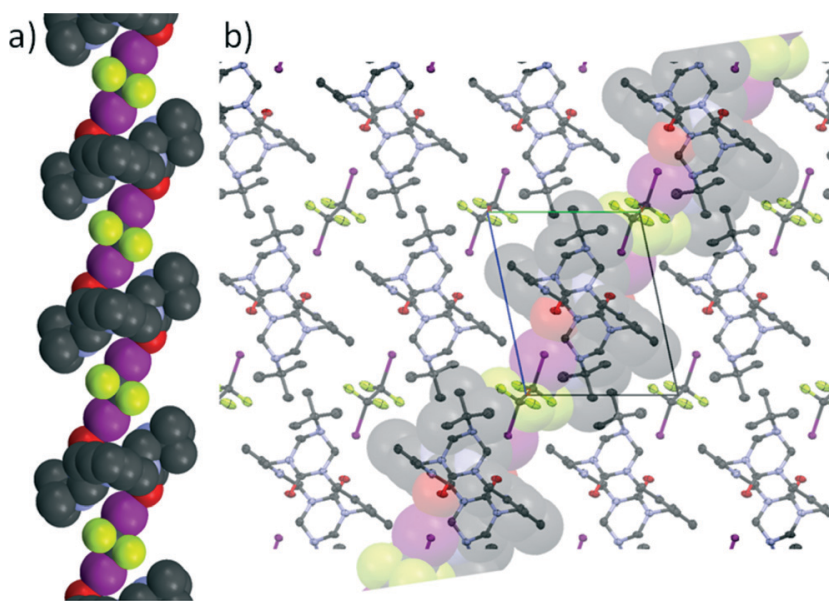

Fig. 5 Crystal structure of macrocycle 1.diiodotetrafluoroethane. a) A space-filling model of the linear chains formed by the halogen bonding interactions. b) The crystal packing with an overlay of the linear chain. (Ellipsoids drawn at the $50 \%$ probability level, C-black, O-red, N-blue, I-purple, F-yellow; hydrogens have been removed for clarity.) 
shows linear chains forming ribbons packed together. Between the ribbons, there is offset aryl-aryl stacking between two adjacent pyridyl macrocycles that displays a ring centroidcentroid distance of $4.04 \AA$ between the parallel rings, with the closest C-C distance being $3.82 \AA$ that aids in the packing.

\section{Ionic salts of pyridyl bis-urea macrocycles}

Macrocycle 1.diiodotetrafluoroethane and light $\left[\left(\mathrm{C}_{28} \mathrm{H}_{38} \mathbf{N}_{8} \mathrm{O}_{2}\right)(\mathrm{I})_{2} \cdot\left(\mathrm{C}_{2} \mathbf{F}_{4} \mathrm{I}_{2}\right) \cdot\left(\mathrm{CDCl}_{3}\right)\right]$. The slow evaporation of a 1:1 mixture of 1 (40 $\mathrm{mM}$ in $\mathrm{CHCl}_{3}$ ) diiodotetrafluoroethane under ambient light resulted in colorless block crystals of $\left(\mathrm{C}_{28} \mathrm{H}_{38} \mathrm{~N}_{8} \mathrm{O}_{2}\right)(\mathrm{I})_{2} \cdot\left(\mathrm{C}_{2} \mathrm{~F}_{4} \mathrm{I}_{2}\right) \cdot\left(\mathrm{CDCl}_{3}\right)$ shown in Fig. 6 . The dicationic macrocycle crystallizes in the triclinic space group $P \overline{\mathbf{1}}$. The asymmetric unit of the crystal consists of one half of macrocycle 1 dication and one iodide anion and one half of a diiodotetrafluoroethane molecule. The asymmetric unit also contains one half of a disordered chloroform molecule with the dication and the diiodotetrafluoroethane species located on crystallographic inversion centers. While the formation of the dication and iodide anion was surprising, lightinduced elimination of the labile iodine across a double bond is a known and reversible reaction. Iodine can oxidize alcohols, sugars and imines to form ketones, glucosamines and dicationic salts. ${ }^{26-30}$ For example, molecular iodine oxidizes 1-methyl-imidazole-2-thione in a $\mathrm{CH}_{2} \mathrm{Cl}_{2}$ solution at the tertiary carbon resulting in a dicationic salt that is useful in thyroid medication. ${ }^{30}$ We surmise that the elimination reaction likely results in the formation of tetrafluoroethene (TFE), which is low boiling ( $\mathrm{bp}=-76.3^{\circ} \mathrm{C}$ ) and would be lost under the ambient conditions of the crystallization. The iodine generated likely oxidizes the triazinanone group resulting in the reduced iodide anion and the imine cation observed in the X-ray structure (Fig. 6a \& b). A carbon in the a)

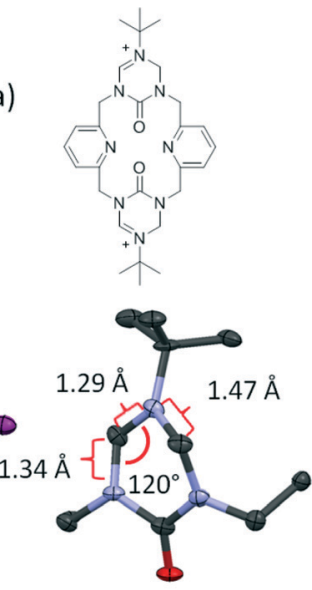

b)

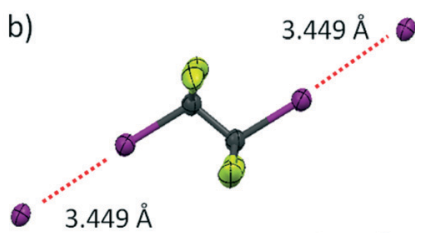

c)

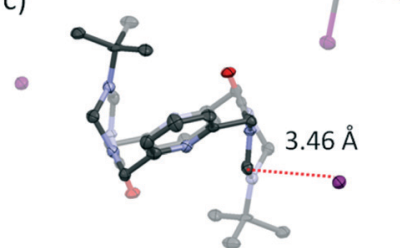

Fig. 6 Selected crystal structure features of $\left.\left[\left(\mathrm{C}_{28} \mathrm{H}_{38} \mathrm{~N}_{8} \mathrm{O}_{2}\right)(\mathrm{I})_{2} \cdot\left(\mathrm{C}_{2} \mathrm{~F}_{4} \mathrm{I}_{2}\right) \cdot(\mathrm{CDCl})_{3}\right)\right]$. a) Schematic representation and crystal structure of deprotonated triazinanone group showing the double bond characteristics formed. b) The iodide anion halogen bonds formed with diiodotetrafluoroethane with an association distance of $3.449 \AA$. c) The ionic bond formed by the macrocycle 1 dication and the iodide anion. (Ellipsoids drawn at the $50 \%$ probability level, C-black, O-red, N-blue, I-purple, F-yellow; hydrogens have been removed for clarity.) triazinanone shows the characteristics of an $\mathrm{sp}^{2}$ hybridization and a double bond character with a $\mathrm{C}-\mathrm{N}$ bond length with the urea nitrogen of 1.289(9) $\AA$ and a $\mathrm{C}-\mathrm{N}$ bond length with the second nitrogen of 1.342(10) A. The bonding angle of the carbon is $120.6(7)^{\circ}$. The bond length, association with the iodine anion, and bond angles suggest that the one carbon of the triazinanone group now has a positive character.

The iodide anions form an ionic bond with the $\mathrm{C}$ in the triazinanone with a $\mathrm{C} \cdots \mathrm{I}^{-}$distance of $3.46 \AA$ (Fig. $6 \mathrm{c}$ ). The two iodide anions are involved in halogen bonds with one diiodotetrafluoroethane. Two halogen bonds formed between the iodide anions and the tetrafluorodiiodoethane molecule with an $\mathrm{I}^{\cdots} \mathrm{I}^{-}$distance of $3.449 \AA$ and a $\mathrm{C}-\mathrm{I} \cdots \mathrm{I}^{-}$angle of $173.80^{\circ}$. This is $87.3 \%$ of the sum of the van der Waals radii of the iodine and iodide anion (3.96 ̊). Fig. 7 shows the crystal packing which has the macrocycles resembling a bodycentered cubic arrangement interspersed with the chloroform, diiodotetrafluoroethane and iodide anions.

\section{Computational examination of halogen bonds}

Our crystal structures demonstrate the formation of short, strong halogen bonds between the urea oxygens of 1 and halides. To further investigate the strengths of the halogen bonding in this complex, electronic structure calculations were performed at the PBE/LANL2DZ level of theory, ${ }^{31}$ using the experimentally acquired crystal structures of macrocycle 1.3 and macrocycle 1.5 complexes. By separating the system into fragments (Fig. 8 and 9) and performing single-point energy calculations, the stabilization energy of each halogen bond was determined.

The first calculations were performed on the macrocycle $\mathbf{1 . 5}$ complex. In the case where both halogen bonding sites were occupied, the halogen bond energy due to group 1 (Fig. 8, G1)

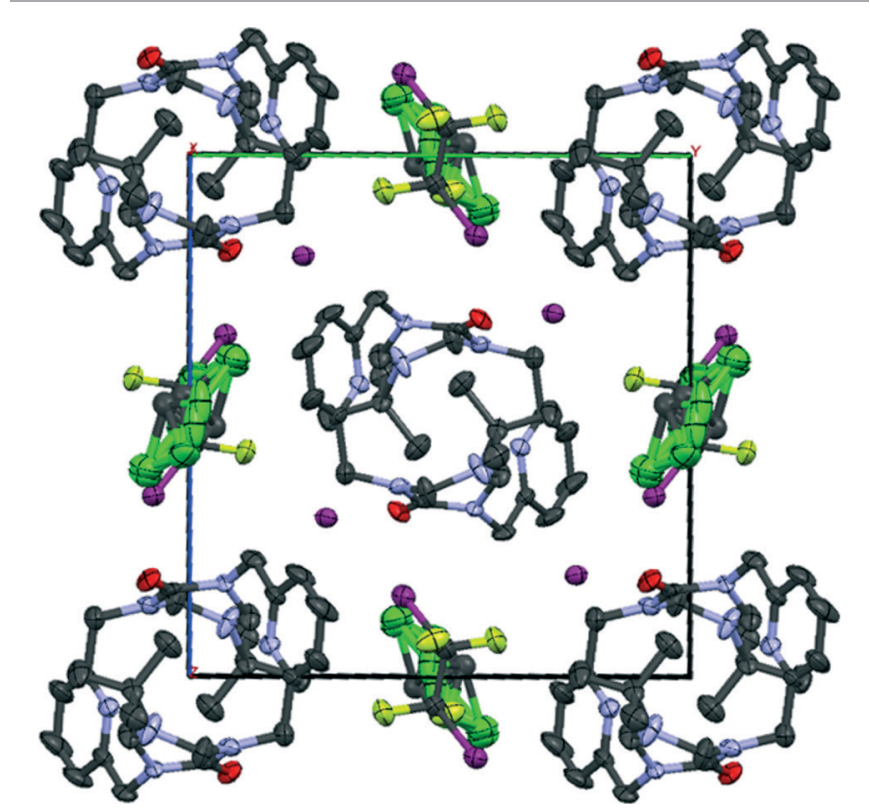

Fig. 7 Crystal packing of $\left[\left(\mathrm{C}_{28} \mathrm{H}_{38} \mathrm{~N}_{8} \mathrm{O}_{2}\right)(\mathrm{I})_{2} \cdot\left(\mathrm{C}_{2} \mathrm{~F}_{4} \mathrm{I}_{2}\right) \cdot\left(\mathrm{CDCl}_{3}\right)\right]$ showing the bodycentered cubic arrangement of macrocycle 1 . 


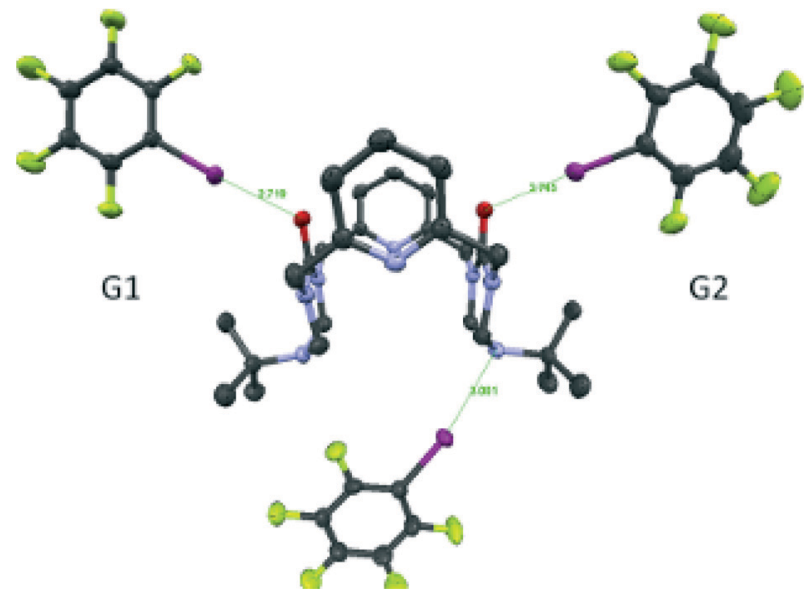

Fig. 8 Group assignment for bond energy calculations.

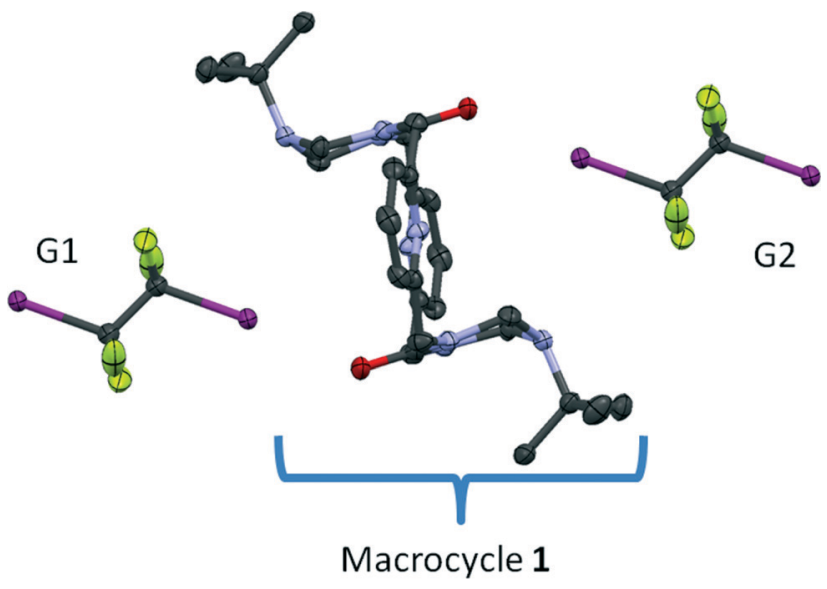

Fig. 9 Group assignment for $\left[\left(\mathrm{C}_{28} \mathrm{H}_{40} \mathrm{~N}_{8} \mathrm{O}_{2}\right) \cdot\left(\mathrm{C}_{2} \mathrm{~F}_{4} \mathrm{I}_{2}\right)\right]$.

was calculated to be $7.465 \mathrm{kcal} \mathrm{mol}^{-1}$. For group 2 (Fig. 8, G2), the halogen bond energy was calculated to be $7.296 \mathrm{kcal} \mathrm{mol}^{-1}$ with an average halogen bond energy for the fully saturated system of $7.381 \mathrm{kcal} \mathrm{mol}^{-1}$. Alternately, if only one halogen bonding site is occupied, the bonding energy is slightly different. In this case, the bonding energy of one substrate is $6.939 \mathrm{kcal} \mathrm{mol}^{-1}$, and the other is $6.769 \mathrm{kcal} \mathrm{mol}^{-1}$, proucing an average of $6.984 \mathrm{kcal} \mathrm{mol}^{-1}$. This suggests that the halogen bonds in the saturated complex are on average $0.527 \mathrm{kcal}$ $\mathrm{mol}^{-1}$ stronger than the unsaturated complex (Table 1 ).

The same computational approach was applied to the macrocycle $\mathbf{1} \cdot \mathbf{3}$ complex. The resulting halogen bond energies for the saturated system were calculated to be 10.332 and $10.330 \mathrm{kcal} \mathrm{mol}^{-1}$ with an average of $10.331 \mathrm{kcal} \mathrm{mol}^{-1}$. For the unsaturated system, the halogen bond energies due to group 1 and group 2 (Fig. 9) were 9.973 and $9.971 \mathrm{kcal} \mathrm{mol}^{-1}$,

Table 1 Computed energies of the halogen bonds ( $\mathrm{kcal} \mathrm{mol}^{-1}$ )

\begin{tabular}{llc}
\hline Complex & Macrocycle 1.5 & Macrocycle 1·3 \\
\hline Saturated average & 7.381 & 10.331 \\
Unsaturated average & 6.984 & 9.972 \\
Difference & 0.527 & 0.359
\end{tabular}

respectively, with an average of $9.972 \mathrm{kcal} \mathrm{mol}^{-1}$. Both complexes have calculated energies that are on the higher end of the halogen bond spectrum as reported by Metrangolo et al. and as seen in the extremely short contact distances. ${ }^{13,32}$ Also of interest is the stabilization effect each substrate has on the other, each of 0.359 and $0.527 \mathrm{kcal} \mathrm{mol}^{-1}$ showing a possible inductive effect through the pyridyl macrocycle that each halogen bond has on the other.

\section{Experimental}

All chemicals were used as received from commercial sources.

\section{General crystallization procedures}

The macrocycle was dissolved in $\mathrm{CH}_{2} \mathrm{Cl}_{2}$, chloroform and THF (40 mM) in separate scintillation vials and mixed with the halogenated compounds in a $1: 1$ or a $1: 2$ molar ratio. The vials were then capped loosely and allowed to slowly evaporate.

X-ray crystal structure determination of protected pyridyl bis-urea macrocycle-pentafluoroiodobenzene complex $\left[\left(\mathbf{C}_{28} \mathbf{H}_{40} \mathbf{N}_{8} \mathbf{O}_{2}\right) \cdot\left(\mathbf{C}_{6} \mathbf{F}_{5} \mathbf{I}\right)_{3}\right]$. X-ray intensity data from an irregular colorless crystal were collected at $100(2) \mathrm{K}$ using a Bruker SMART APEX diffractometer (Mo K $\alpha$ radiation, $\lambda=0.71073 \AA$ ). The data crystal was cleaved from an undifferentiated mass of crystalline solid. The raw area detector data frames were reduced and corrected for absorption effects with the SAINT+ and SADABS programs. The final unit cell parameters were determined by least-squares refinement of 6627 reflections from the data set. Direct method structure solution, difference Fourier calculations and full-matrix least-squares refinement against $F^{2}$ were performed with SHELXS/ $/ \mathrm{L}^{36}$ as implemented in OLEX2. ${ }^{37}$

The compound crystallizes in the triclinic system (Table 2). The space group $P \overline{1}$ (no. 2) was confirmed by the successful solution and refinement of the structure. The asymmetric unit consists of one $\mathrm{C}_{28} \mathrm{H}_{40} \mathrm{~N}_{8} \mathrm{O}_{2}$ molecule and three independent $\mathrm{C}_{6} \mathrm{~F}_{5} \mathrm{I}$ molecules. All non-hydrogen atoms were refined with anisotropic displacement parameters. Hydrogen atoms were placed in geometrically idealized positions and included as riding atoms. The largest residual electron density peaks of ca. 1 e $\AA^{-3}$ are located $<1 \AA$ from the three independent iodine atoms.

X-ray crystal structure determination of protected pyridyl bis-urea macrocycle-diiodotetrafluoroethane complex $\left[\left(\mathrm{C}_{28} \mathbf{H}_{40} \mathbf{N}_{8} \mathbf{O}_{2}\right) \cdot\left(\mathbf{C}_{2} \mathbf{F}_{4} \mathbf{I}_{2}\right)\right]$. X-ray intensity data from a colorless platelike crystal were collected at 100(2) K using a Bruker SMART APEX diffractometer (Mo K $\alpha$ radiation, $\lambda=0.71073 \AA$ ). ${ }^{33-35}$ The raw area detector data frames were reduced and corrected for absorption effects with the SAINT+ and SADABS programs. The final unit cell parameters were determined by leastsquares refinement of 4619 reflections from the data set. Direct method structure solution, difference Fourier calculations and full-matrix least-squares refinement against $F^{2}$ were performed with SHELXS/ $/ \mathrm{L}^{36}$ as implemented in OLEX2. ${ }^{37}$

The compound crystallizes in the triclinic system (Table 2). The space group $P \overline{1}$ (no. 2) was determined by structure 
Table 2 Crystal and refinement data for complexes $\left[\left(\mathrm{C}_{28} \mathrm{H}_{40} \mathrm{~N}_{8} \mathrm{O}_{2}\right) \cdot\left(\mathrm{C}_{6} \mathrm{~F}_{5}\right)_{3}\right],\left[\left(\mathrm{C}_{28} \mathrm{H}_{40} \mathrm{~N}_{8} \mathrm{O}_{2}\right) \cdot\left(\mathrm{C}_{2} \mathrm{~F}_{4} \mathrm{I}_{2}\right)\right]$, and $\left[\left(\mathrm{C}_{28} \mathrm{H}_{38} \mathrm{~N}_{4} \mathrm{O}_{2}\right)(\mathrm{I})_{2} \cdot\left(\mathrm{C}_{2} \mathrm{~F}_{4} \mathrm{I}_{2}\right)_{2}\right]$

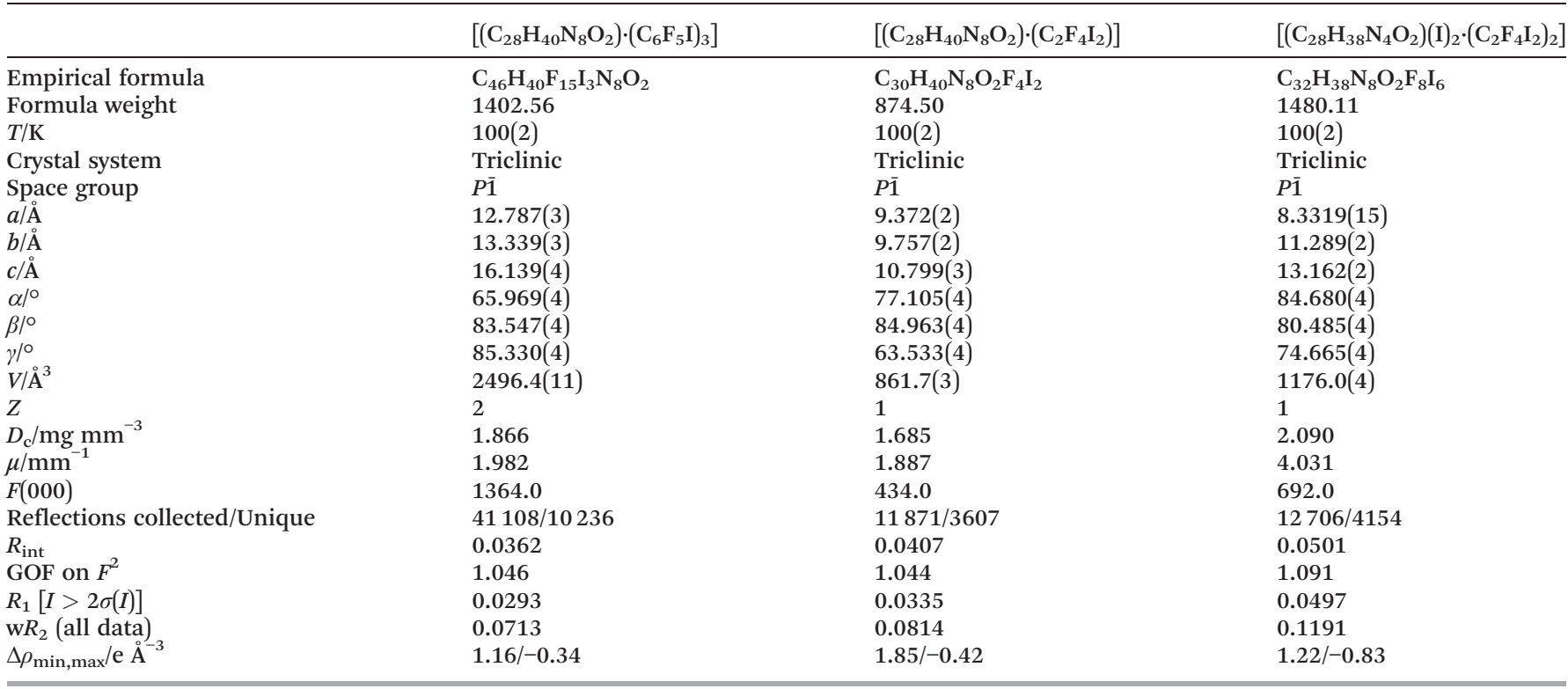

solution. The asymmetric unit consists of half of one $\mathrm{C}_{28} \mathrm{H}_{40} \mathrm{~N}_{8} \mathrm{O}_{2}$ molecule and half of one $\mathrm{C}_{2} \mathrm{~F}_{2} \mathrm{I}_{2}$ molecule, both of which are located on crystallographic inversion centers. Nonhydrogen atoms were refined with anisotropic displacement parameters. Hydrogen atoms were placed in geometrically idealized positions and included as riding atoms. The largest

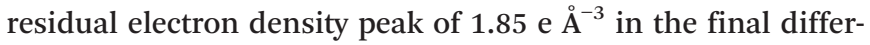
ence map is located $0.92 \AA$ from the unique iodine atom I(1).

$\mathrm{X}$-ray crystal structure determination of protected pyridyl bis-urea macrocycle-diiodotetrafluoroethane complex $\left[\left(\mathrm{C}_{28} \mathrm{H}_{38} \mathbf{N}_{4} \mathrm{O}_{2}\right)(\mathrm{I})_{2} \cdot\left(\mathrm{C}_{2} \mathbf{F}_{4} \mathrm{I}_{2}\right)_{2}\right]$. X-ray intensity data from a colorless blocklike crystal were collected at 100(2) $\mathrm{K}$ using a Bruker SMART APEX diffractometer (Mo $\mathrm{K} \alpha$ radiation, $\lambda=$ $0.71073 \AA) .{ }^{33-35}$ The raw area detector data frames were reduced and corrected for absorption effects with the SAINT+ and SADABS programs. ${ }^{33-35}$ The final unit cell parameters were determined by least-squares refinement of 2405 reflections from the data set. Direct method structure solution, difference Fourier calculations and full-matrix least-squares refinement against $F^{2}$ were performed with $\mathrm{SHELXS} / \mathrm{L}^{36}$ as implemented in OLEX2. ${ }^{37}$

The compound crystallizes in the triclinic system (Table 2). The space group $P \overline{1}$ (no. 2) was confirmed by the successful solution and refinement of the structure. The asymmetric unit consists of half of one $\mathrm{C}_{28} \mathrm{H}_{38} \mathrm{~N}_{4} \mathrm{O}_{2}{ }^{2+}$ cationic cycle located on a crystallographic inversion center, one iodide anion, half of one $\mathrm{C}_{2} \mathrm{~F}_{4} \mathrm{I}_{2}$ molecule also located on a crystallographic inversion center, and an essentially continuously disordered volume of electron density running parallel to the crystallographic $a$ axis direction, centered at $y=0.5, z=0$. Based on trial refinements of the strongest peaks in the region, this electron density represents one $\mathrm{C}_{2} \mathrm{~F}_{4} \mathrm{I}_{2}$ molecule per cycle. Attempts to model this density with discrete $\mathrm{C}_{2} \mathrm{~F}_{4} \mathrm{I}_{2}$ groups failed, and it was therefore modeled with a total of five fractionally occupied iodine atom positions, eight fluorine positions and three carbon atom positions. Free refinement of the occupancy values of the five iodine positions yielded 1.94I per cycle, supporting the reported stoichiometry. Occupancies of the $\mathrm{C}$, $\mathrm{F}$, and I sites were constrained to a sum of one $\mathrm{C}_{2} \mathrm{~F}_{4} \mathrm{I}_{2}$ molecule per cycle, and atoms of the same kind were assigned a common isotropic displacement parameter. No restraints were applied to simulate the expected molecular geometry or bond distances for these atoms. All other non-hydrogen atoms were refined with anisotropic displacement parameters. Hydrogen atoms bonded to carbon were located in difference maps before being placed in geometrically idealized positions and included as riding atoms. The largest residual electron density peak in the final difference map is located $1.0 \AA$ from the iodide anion I(1).

\section{Conclusions}

The co-crystallization of the pyridyl bis-urea macrocycle with two halogen bond donors, diiodotetrafluoroethane and iodopentafluorobenzene, by slow evaporation from dichloride methane resulted in very strong halogen bonds. The bonds formed with the carbonyl oxygen of the urea in macrocycle 1 and were an average of $78 \%$ of the van der Waals radii for

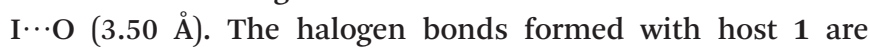
shorter than charged analogs reported by Metrangolo and Resnati. Indeed, if we equate bond length with bond strength, co-crystal formation host 1 with electrophilic halides affords among the strongest halogen bonding motif surveyed by Metrangolo in the CSD. ${ }^{38}$ Through DFT calculation, we estimated these energies to be $7.381 \mathrm{kcal} \mathrm{mol}^{-1}$ for the iodopentafluorobenzene halogen bond and $10.331 \mathrm{kcal}$ $\mathrm{mol}^{-1}$ for the iodotetrafluoroethane halogen bond. We are currently investigating the strength of these interactions through NMR and X-ray photoelectron spectroscopy studies and hope to report on these in due course. We expect that the propensity for strong halogen bond formation will be 
conserved upon the deprotection of the triazinanone groups on the self-assembling urea 2 . This new assembly unit combines both hydrogen bonding donors and multiple acceptors for hydrogen or halogen bonds and should result in cocrystalline materials that preorganize and enhance the chemical and electronic properties.

\section{Acknowledgements}

The authors gratefully acknowledge partial support for this work from NSF grants CHE-1012298, CHE-1048629 (computational center) and CHE-1056188 (for J.M.). M.F.G. acknowledges a University of South Carolina College of Arts and Sciences Dean's Dissertation Fellowship.

\section{References}

1 A. Priimagi, M. Saccone, G. Cavallo, A. Shishido, T. Pilati, P. Metrangolo and G. Resnati, Adv. Mater., 2012, 24, OP345-OP352.

2 A. Priimagi, G. Cavallo, A. Forni, M. Gorynsztejn-Leben, M. Kaivola, P. Metrangolo, R. Milani, A. Shishido, T. Pilati, G. Resnati and G. Terraneo, Adv. Funct. Mater., 2012, 22, 2572-2579.

3 H. L. Nguyen, P. N. Horton, M. B. Hursthouse, A. C. Legon and D. W. Bruce, J. Am. Chem. Soc., 2003, 126, 16-17.

4 J. W. Lauher, F. W. Fowler and N. S. Goroff, Acc. Chem. Res., 2008, 41, 1215-1229.

5 C. M. Cho, X. Wang, J. J. Li, C. He and J. Xu, Liq. Cryst., 2012, 1-12.

6 D. W. Bruce, P. Metrangolo, F. Meyer, T. Pilati, C. Praesang, G. Resnati, G. Terraneo, S. G. Wainwright and A. C. Whitwood, Chem.-Eur. J., 2010, 16, 9511-9524.

7 M. Fourmigué and P. Batail, Chem. Rev., 2004, 104, 5379-5418.

8 N. Muzet, B. Guillot, C. Jelsch, E. Howard and C. Lecomte, Proc. Natl. Acad. Sci. U. S. A., 2003, 100, 8742-8747.

9 M. Kolar, P. Hobza and A. K. Bronowska, Chem. Commun., 2013, 49, 981-983.

10 F. A. Hays, J. M. Vargason and P. S. Ho, Biochemistry, 2003, 42, 9586-9597.

11 G. W. Gribble, Acc. Chem. Res., 1998, 31, 141-152.

12 P. Auffinger, F. A. Hays, E. Westhof and P. S. Ho, Proc. Natl. Acad. Sci. U. S. A., 2004, 101, 16789-16794.

13 P. Metrangolo, F. Meyer, T. Pilati, G. Resnati and G. Terraneo, Angew. Chem., Int. Ed., 2008, 47, 6114-6127.

14 P. Metrangolo, H. Neukirch, T. Pilati and G. Resnati, Acc. Chem. Res., 2005, 47, 6114-6127.

15 J. Yang, M. B. Dewal, D. Sobransingh, M. D. Smith, Y. W. Xu and L. S. Shimizu, J. Org. Chem., 2009, 74, 102-110.

16 J. Yang, M. B. Dewal and L. S. Shimizu, J. Am. Chem. Soc., 2006, 128, 8122-8123.

17 L. S. Shimizu, M. D. Smith, A. D. Hughes and K. D. Shimizu, Chem. Commun., 2001, 1592-1593.

18 M. B. Dewal, M. W. Lufaso, A. D. Hughes, S. A. Samuel, P. Pellechia and L. S. Shimizu, Chem. Mater., 2006, 18, 4855-4864.
19 K. Roy, C. Wang, M. D. Smith, M. B. Dewal, A. C. Wibowo, J. C. Brown, S. G. Ma and L. S. Shimizu, Chem. Commun., 2011, 47, 277-279.

20 Spartan'10, Wavefunction, Inc., Irvine, CA.

21 M. T. Messina, P. Metrangolo, W. Panzeri, T. Pilati and G. Resnati, Tetrahedron, 2001, 57, 8543-8550.

22 L. S. Shimizu, A. D. Hughes, M. D. Smith, S. A. Samuel and D. Ciurtin-Smith, Supramol. Chem., 2005, 17, 27-30.

23 L. S. Shimizu, A. D. Hughes, M. D. Smith, M. J. Davis, B. P. Zhang, H. C. zur Loye and K. D. Shimizu, J. Am. Chem. Soc., 2003, 125, 14972-14973.

24 Q. Chu, Z. Wang, Q. Huang, C. Yan and S. Zhu, New J. Chem., 2003, 27, 1522-1527.

25 Q. Chu, Z. Wang, Q. Huang, C. Yan and S. Zhu, J. Am. Chem. Soc., 2001, 123, 11069-11070.

26 H. Togo and S. Iida, Synlett, 2006, 2159-2175.

27 M. J. Mphahlele, Molecules, 2009, 14, 5308-5322.

28 M. B. Fusaro, V. Chagnault and D. Postel, Tetrahedron, 2013, 69, 542-550.

29 L. Colombeau, T. Traoré, P. Compain and O. R. Martin, J. Org. Chem., 2008, 73, 8647-8650.

30 M. C. Aragoni, M. Arca, F. Demartin, F. A. Devillanova, A. Garau, F. Isaia, V. Lippolis and G. Verani, J. Am. Chem. Soc., 2002, 124, 4538-4539.

31 Y. Shao, L. F. Molnar, Y. Jung, J. Kussmann, C. Ochsenfeld, S. T. Brown, A. T. B. Gilbert, L. V. Slipchenko, S. V. Levchenko, D. P. O'Neill, R. A. DiStasio Jr, R. C. Lochan, T. Wang, G. J. O. Beran, N. A. Besley, J. M. Herbert, C. Yeh Lin, T. Van Voorhis, S. Hung Chien, A. Sodt, R. P. Steele, V. A. Rassolov, P. E. Maslen, P. P. Korambath, R. D. Adamson, B. Austin, J. Baker, E. F. C. Byrd, H. Dachsel, R. J. Doerksen, A. Dreuw, B. D. Dunietz, A. D. Dutoi, T. R. Furlani, S. R. Gwaltney, A. Heyden, S. Hirata, C.-P. Hsu, G. Kedziora, R. Z. Khalliulin, P. Klunzinger, A. M. Lee, M. S. Lee, W. Liang, I. Lotan, N. Nair, B. Peters, E. I. Proynov, P. A. Pieniazek, Y. Min Rhee, J. Ritchie, E. Rosta, C. D. Sherrill, A. C. Simmonett, J. E. Subotnik, H. Lee Woodcock, W. Zhang, A. T. Bell, A. K. Chakraborty, D. M. Chipman, F. J. Keil, A. Warshel, W. J. Hehre, H. F. Schaefer, J. Kong, A. I. Krylov, P. M. W. Gill and M. Head-Gordon, Phys. Chem. Chem. Phys., 2006, 8, 3172-3191.

32 P. Metrangolo and G. Resnati, Chem.-Eur. J., 2001, 7, 2511-2519.

33 SMART, Bruker Analytical X-ray Systems Inc., Madison, Wisconsin, USA, 2003.

34 SAINT+, Bruker Analytical X-ray Systems Inc., Madison, Wisconsin, USA, 2003.

35 SADABS, Bruker Analytical X-ray Systems, Madison, Wisconsin, USA, 2003.

36 G. M. Sheldrick, Acta Crystallogr., Sect. A: Found. Crystallogr., 2008, 64, 112-122.

37 O. V. Dolomanov, L. J. Bourhis, R. J. Gildea, J. A. K. Howard and H. Puschmann, J. Appl. Crystallogr., 2009, 42, 339-341.

38 P. Metrangolo and G. Resnati, Cryst. Growth Des., 2012, 12, 5835-5838. 